\title{
Pillar[5]arene-Based Solid-State Supramolecular Polymers with Suppressed Aggregation-Caused Quenching Effects and Two-Photon Excited Emission
}

Bin Hua, ${ }^{\dagger, ~}$ "Chi Zhang,,, \# Wei Zhou, ${ }^{\neq}$Li Shao, ${ }^{+}$Zedong Wang, ${ }^{\xi}$ Linjun Wang, ${ }^{\xi}$ Haiming Zhu ${ }^{*, \neq}$ and Feihe Huang ${ }^{*}+$, s

${ }^{\dagger}$ State Key Laboratory of Chemical Engineering, Center for Chemistry of High-Performance \& Novel Materials, Department of Chemistry, Zhejiang University, Hangzhou 310027, P. R. China.

* State Key Laboratory of Modern Optical Instrumentation, Center for Chemistry of High-Performance \& Novel Materials, Department of Chemistry, Zhejiang University, Hangzhou 310027, P. R. China.

${ }^{\xi}$ Center for Chemistry of High-Performance \& Novel Materials, Department of Chemistry, Zhejiang University, Hangzhou 310027, P. R. China.

${ }^{\Im}$ Green Catalysis Center and College of Chemistry, Zhengzhou University, Zhengzhou 450001, P. R. China.

Fax and Tel: +86-571-8795-3189; Email: hmzhu@zju.edu.cn; fhuang@zju.edu.cn.

\section{Supporting Information}

1. Materials and methods $\quad$ S2

2. The crystal structures of DTBT and DTBS S3

3. The aggregation caused quenching effects of DTBT and DTBS S3

4. The electrostatic potential maps of DTBT, DTBS and PrP5 S4

5. ${ }^{1} H$ NMR spectra of solutions of DTBT and DTBS with PrP5 S5

6. NOESY NMR spectra of solutions of DTBT and DTBS with PrP5 S6

7. ${ }^{1} H$ NMR titration experiments for the host-guest complexation of DTBT and $\begin{array}{ll}\text { DTBS with PrP5 } & \text { S7 }\end{array}$

8. Concentration-dependent ${ }^{1} H$ NMR studies of DTBS and PrP5 in $\mathrm{CDCl}_{3} \quad \mathrm{~S} 12$

9. Concentration dependence of the diffusion coefficients of DTBT and DTBS with PrP5 in $\mathrm{CDCl}_{3} \quad \mathrm{~S} 13$

10. X-ray crystal data of PrP5 $D$ DTBT and PrP5 $\triangle D T B S \quad S 14$

11. The PL/PLE spectra and TCSPC decay curves of DTBS and PrP5دDTBS S16

12. Photographs of DTBT, PrP5 $\triangle D T B T$, DTBS, and PrP5 $\triangle$ DTBS under a UV $\begin{array}{ll}\text { lamp } & \text { S17 }\end{array}$

13. TCSPC decay curves of DTBT, DTBS, PrP5 $\triangle D T B T$, and PrP5 $\triangle D T B S$ $\begin{array}{ll}\text { crystals } & \mathrm{S} 18\end{array}$

14. References $\quad \mathrm{S} 18$ 


\section{Materials and methods}

All reagents were commercially available and used as supplied without further purification. Solvents were either employed as purchased or dried according to procedures described in the literature. Compounds PrP5 ${ }^{\mathrm{S} 1}$ and $\mathbf{D T B S}{ }^{\mathrm{S} 2}$ were synthesized according to previous literature. NMR spectra were recorded with a Bruker Avance DMX 600 spectrophotometer or a Bruker Avance DMX 500 spectrophotometer with the deuterated solvent as the lock and the residual solvent or TMS as the internal reference. The fluorescence experiments were conducted on an RF-5301 spectrofluorophotometer (Shimadzu Corporation, Japan). Quantum yield measurements were performed using the absolute method on a FLS920 from Edinburgh Instruments equipped with a $\mathrm{BaSO}_{4}$-coated integrating sphere, a 450W Xe900 Xenon lamp and a R928P PMT detector.

\section{Optical Characterization}

The optical measurements were taken on a home-built far-field microfluorescence system (Olympus, IX73 inverted microscope). The samples were placed on a transparent glass substrate. The excitation light $(460 \mathrm{~nm})$ was generated from the second harmonic of the fundamental output that was seeded by a mode-locked Ti:sapphire laser (Light Conversion Pharos, $1030 \mathrm{~nm},<300 \mathrm{fs}, 1 \mathrm{MHz}$ ). After going through a series of mirrors, the excitation light was filtered with a $500 \mathrm{~nm}$ premium short-pass filter (Thorlab, FESH0500) to filter out other wavelengths of light, and finally focused down to a $10 \mu \mathrm{m}$ diameter spot through an objective lens (Olympus MplanFLN, 20x, NA = 0.45). The fluorescence was collected by the same objective and focused into a spectrograph (Princeton Instruments, Acton SpectraPro, SP-2300i ) with a $600 \mathrm{~mm}^{-1}$ grating and detected by a liquid-N $\mathrm{N}_{2}$-cooled CCD (PyLon 100B excelon). The instrument resolution (FWHM) was $\sim 0.1 \mathrm{~nm}$. TRPL decay kinetics were collected using a TCSPC module (PicoHarp 300) and a SPAD detector (IDQ, id100) with an instrument response function $\sim 100$ ps. The two-photon excited fluorescence was measured upon excitation at $1030 \mathrm{~nm}$; the settings were similar to the former except that the filter on the optical path was replaced with a $700 \mathrm{~nm}$ long-pass filter to filter out other wavelengths of light. 
2. The crystal structures of DTBT and DTBS

(a)

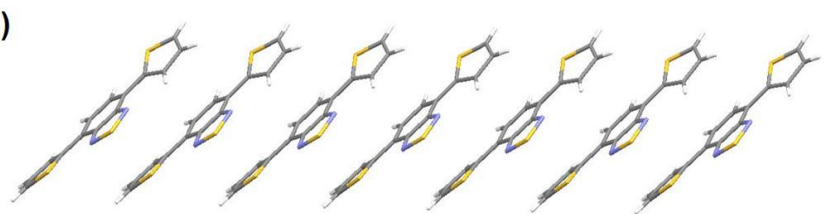

(b)

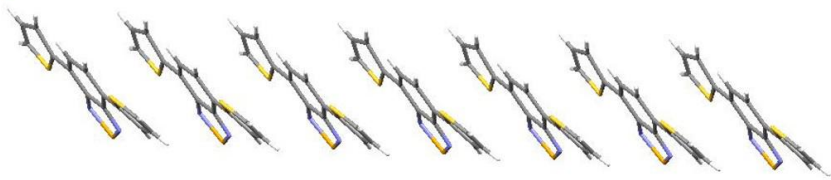

Figure S1 The crystal structures of (a) DTBT and (b) DTBS. CCDC number 1817464 and 961060.

3. The aggregation caused quenching effects of DTBT and DTBS

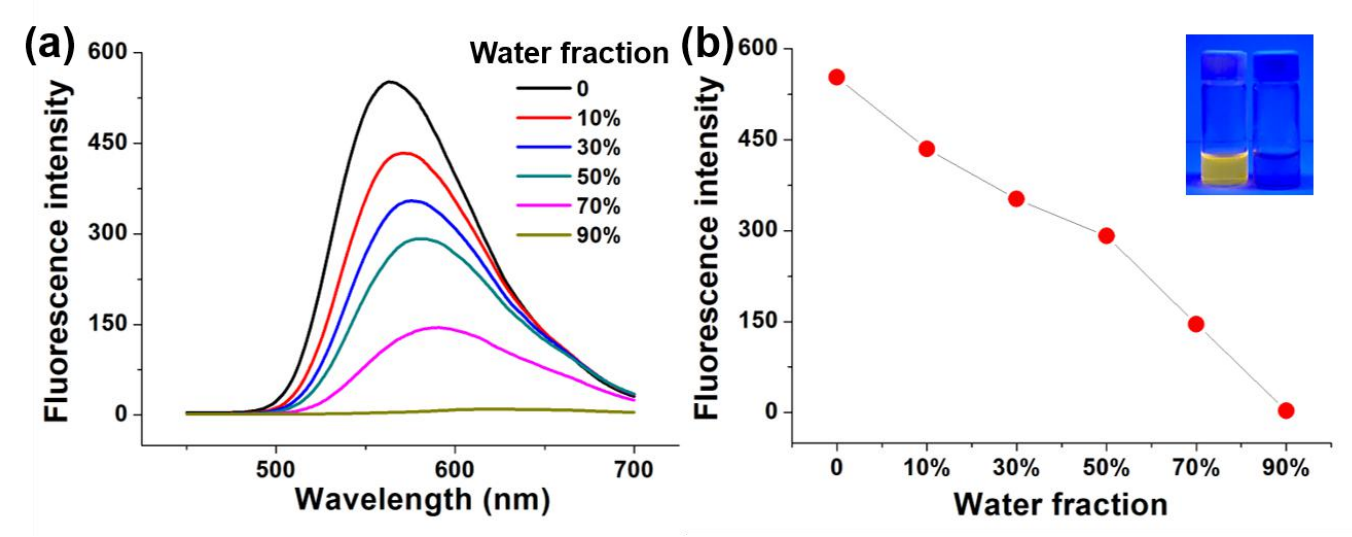

Figure S2 (a) Fluorescence spectra and (b) a plot of fluorescence intensity of DTBT $\left(5 \mu \mathrm{M}, \lambda_{\mathrm{ex}}=400 \mathrm{~nm}\right)$ in THF-water mixture with different water fractions.
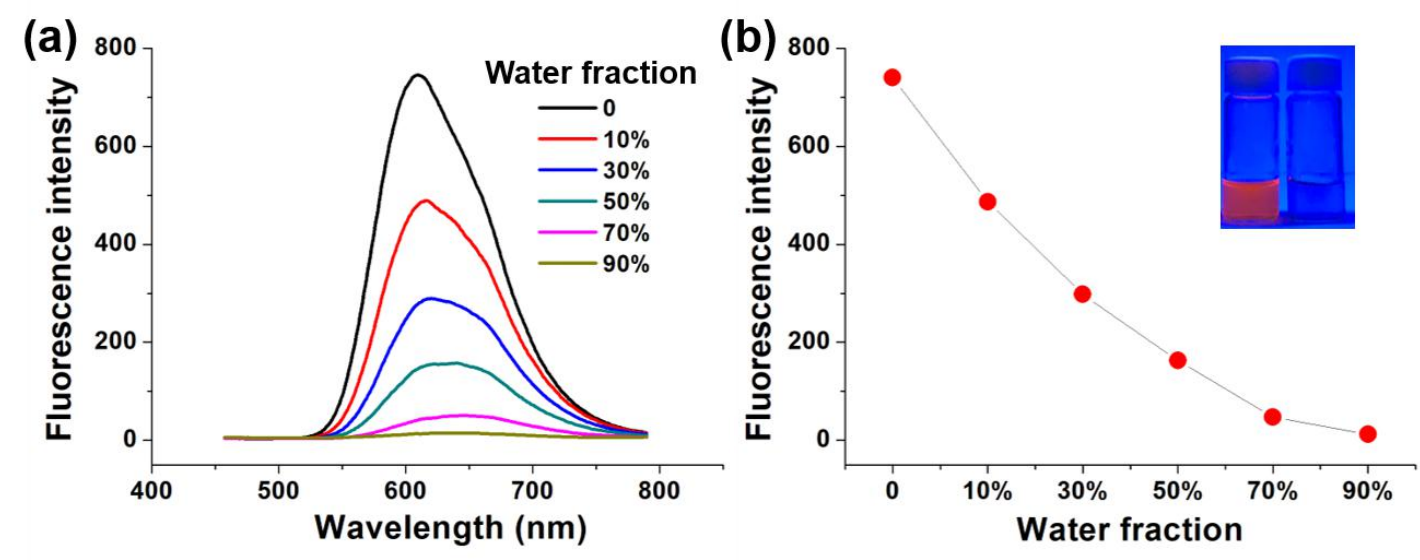

Figure S3 (a) Fluorescence spectra and (b) a plot of fluorescence intensity of DTBS $\left(5 \mu \mathrm{M}, \lambda_{\mathrm{ex}}=400 \mathrm{~nm}\right)$ in $\mathrm{THF}-$ water mixture with different water fractions. 
As an increasing fraction of water was added to a THF solution of DTBT or DTBS, the fluorescence intensity of the solution decreased, indicating the inherent ACQ effects of the dyes.

\section{The electrostatic potential maps of DTBT, DTBS and PrP5}

(a)

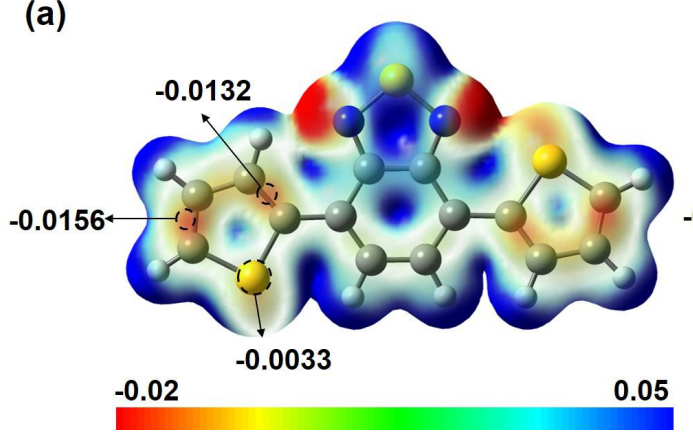

(b)

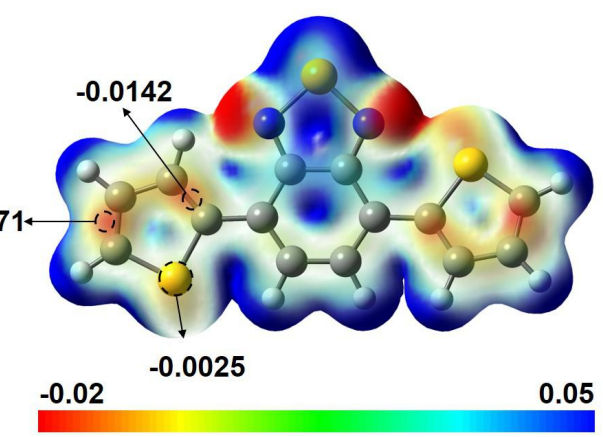

Figure S4 Chemical structures and distributions of the electrostatic potential mapped onto the electron density surfaces of (a) DTBT and (b) DTBS.

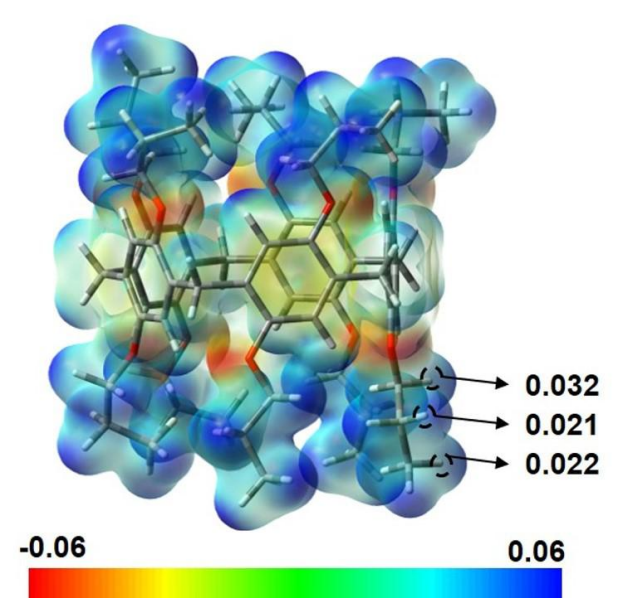

Figure S5 Chemical structure and distributions of the electrostatic potential mapped onto the electron density surfaces of PrP5.

The individual molecules (i.e., DTBT, DTBS, and PrP5) were firstly relaxed by the density functional theory (DFT) at the B3LYP/6-31G(d,p) level with the Gaussian 16 package. ${ }^{\mathrm{S} 3}$ To reveal the underlying mechanism of two-phonon absorption strength and molecular packing between DTBT (or DTBS) and PrP5, we then calculate the molecular electrostatic potential (MESP) ${ }^{\mathrm{S} 4}$ mapped onto the electron density surface. In detail, the MESP at a specified point $\mathbf{r}$ around the molecule is defined as

$$
V(\mathbf{r})=\sum_{A} \frac{Z_{A}}{\left|\mathbf{R}_{A}-\mathbf{r}\right|}-\int \frac{\rho\left(\mathbf{r}^{\prime}\right) d \mathbf{r}^{\prime}}{\left|\mathbf{r}^{\prime}-\mathbf{r}\right|},
$$


where $\rho(\mathbf{r})$ is the electron density distribution, $Z_{A}$ and $\mathbf{R}_{A}$ are the charge and position of nucleus $A$, respectively. In Eq. (S1), atomic units have been utilized to simplify the expressions. $V(\mathbf{r})$ can be regarded as the energy required to move a positive unit point charge from infinity to the point $\mathbf{r}$. Thereby, positive and negative values of $V(\mathbf{r})$ indicate electrophilic and nucleophilic properties around point $\mathbf{r}$, respectively. The visualization of MESP is realized with an isosurface value for the electron density of $0.01 e / a^{3}$ by the Gaussview software, ${ }^{\mathrm{S} 5}$ where $a$ is the Bohr radius.

\section{5. ${ }^{1} H$ NMR spectra of solutions of DTBT and DTBS with PrP5}

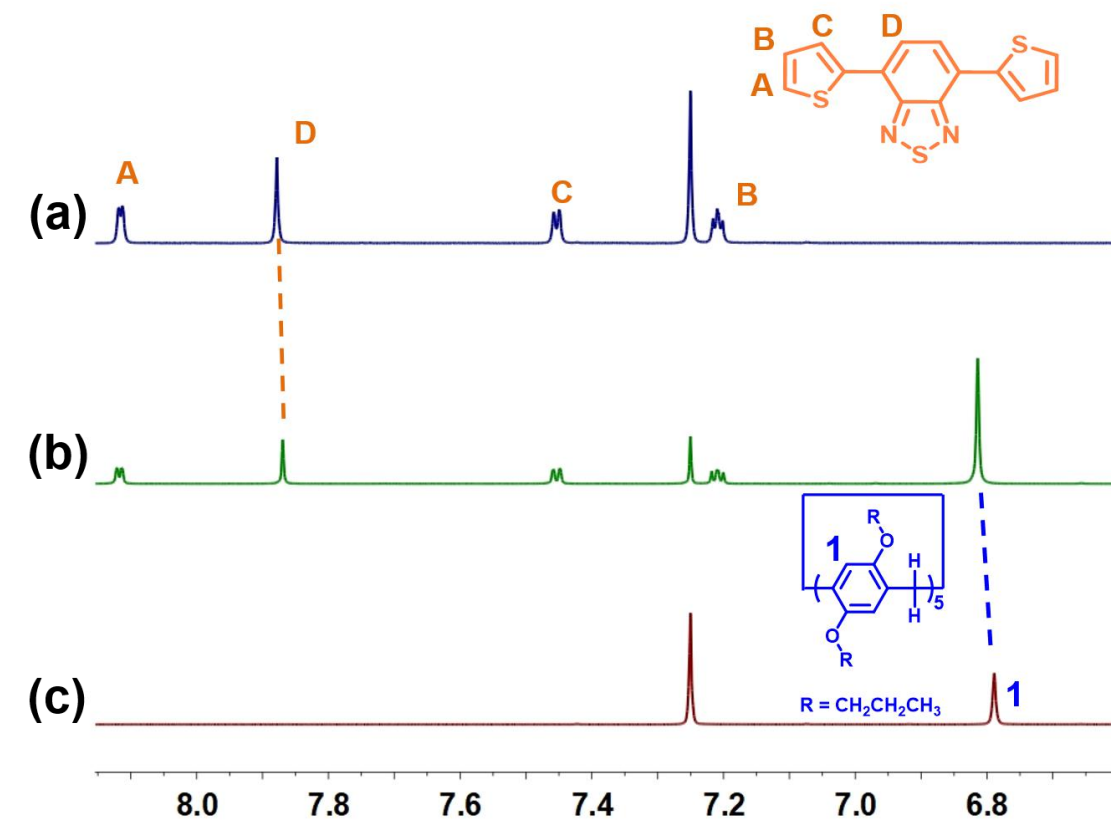

Figure S6 Partial ${ }^{1} \mathrm{H}$ NMR spectra (500 MHz, $\mathrm{CDCl}_{3}, 293 \mathrm{~K}$ ): (a) DTBT; (b) an equimolar (25.0 mM) solution of DTBT and PrP5; (c) PrP5.

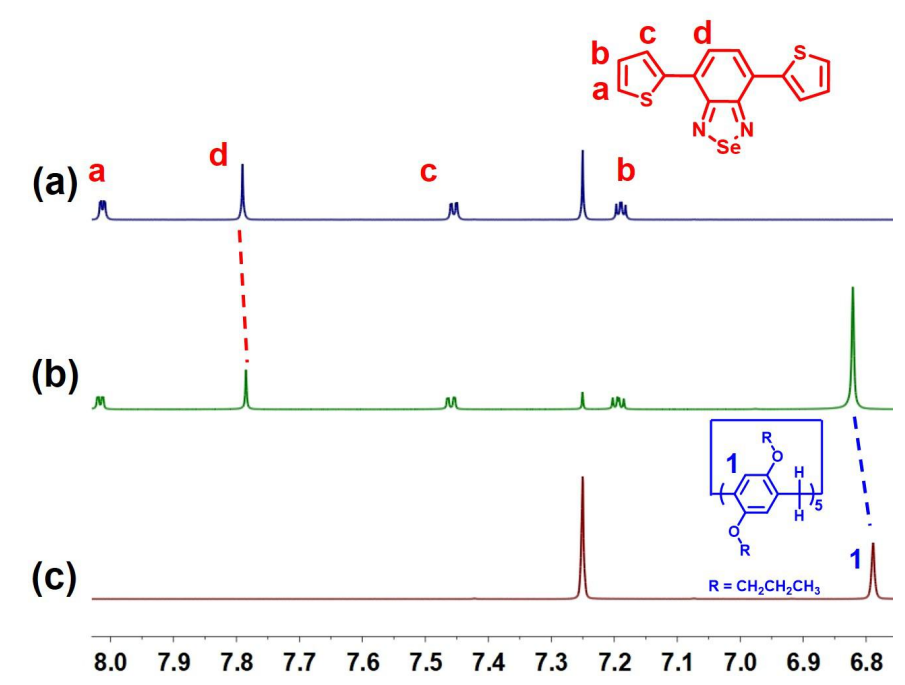


Figure S7 Partial ${ }^{1} \mathrm{H}$ NMR spectra (500 MHz, $\mathrm{CDCl}_{3}, 293 \mathrm{~K}$ ): (a) DTBS; (b) an equimolar (25.0 mM) solution of DTBS and PrP5; (c) PrP5.

6. NOESY NMR spectra of solutions of DTBT or DTBS with PrP5

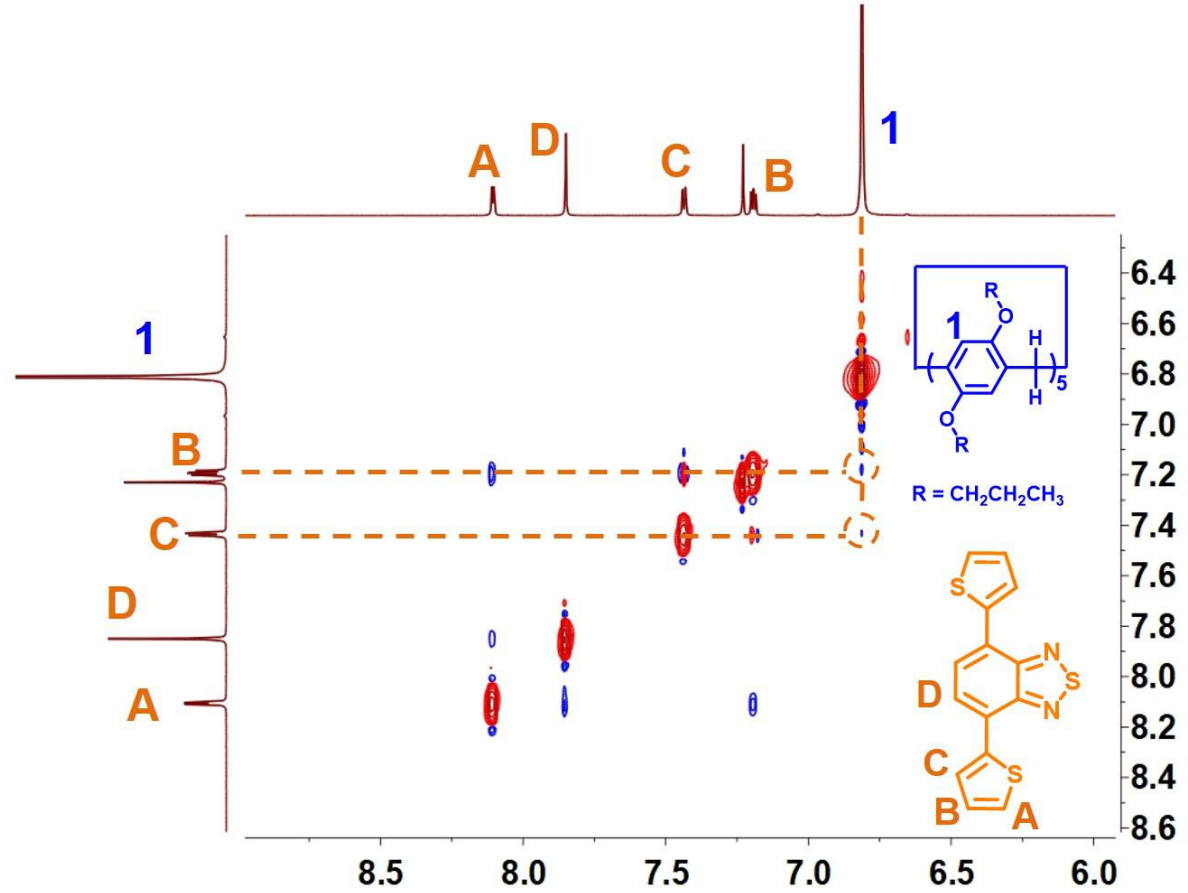

Figure S8 Partial NOESY NMR spectrum (500 MHz, $\mathrm{CDCl}_{3}, 293 \mathrm{~K}$ ) of a solution of DTBT (5.00 mM) and PrP5 (8.00 mM).

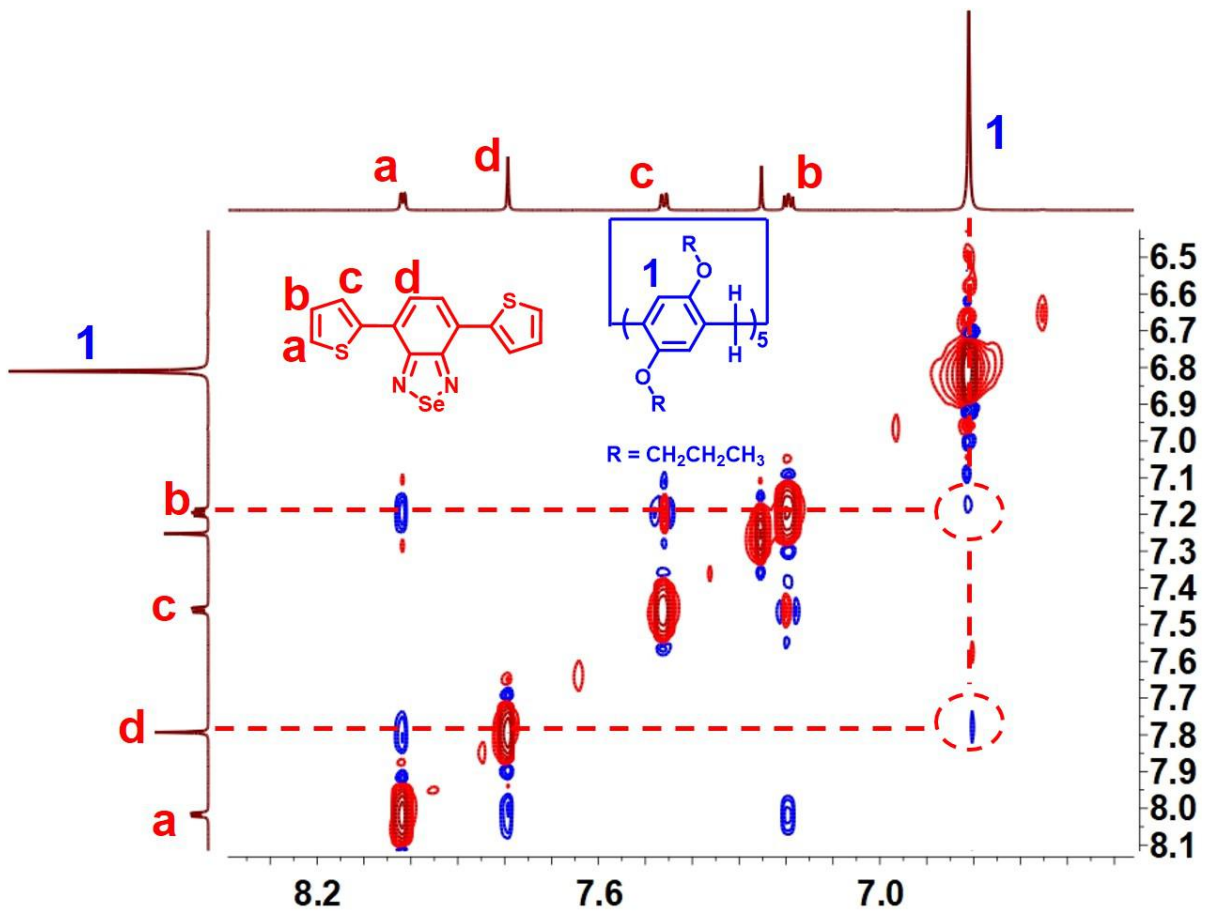

Figure S9 Partial NOESY NMR spectrum (500 $\mathrm{MHz}, \mathrm{CDCl}_{3}, 293 \mathrm{~K}$ ) of an equimolar (10.00 mM) solution of DTBS and PrP5. 
7. ${ }^{1} H$ NMR titration experiments for the host-guest complexation of DTBT and DTBS with PrP5

To determine the stoichiometry and association constant between PrP5 and guests $\mathbf{G}$ (DTBT and DTBS), ${ }^{1} \mathrm{H}$ NMR titration was done with solutions which had a constant concentration of $\mathbf{G}(1.00 \mathrm{mM})$ and varying concentrations of PrP5. By a non-linear curve-fitting method, the association constant between guest $\mathbf{G}$ and host PrP5 was calculated. The non-linear curve-fitting was based on the equation: ${ }^{\mathrm{S} 6}$

$$
\begin{aligned}
\Delta \delta=\left(\Delta \delta_{\infty} /[\mathbf{G}]_{0}\right)\left(0.5[\mathbf{P r P 5}]_{0}+\right. & 0.5\left([\mathbf{G}]_{0}+1 / K_{\mathrm{a}}\right)-\left(0 . 5 \left([\mathbf{P r P 5}]_{0}{ }^{2}+\left(2[\mathbf{P r P 5}]_{0}\left(1 / K_{\mathrm{a}}-[\mathbf{G}]_{0}\right)\right)\right.\right. \\
& \left.\left.\left.+\left(1 / K_{\mathrm{a}}+[\mathbf{G}]_{0}\right)^{2}\right)^{0.5}\right)\right)
\end{aligned}
$$

Where $\Delta \delta$ is the chemical shift change of a proton on $\mathbf{G}$ at $[\mathbf{P r P 5}]_{0}, \Delta \delta_{\infty}$ is the chemical shift change of the proton when the guest is completely complexed, $[\mathbf{G}]_{0}$ is the fixed initial concentration of the guest, and $[\mathbf{P r P 5}]_{0}$ is the varying concentrations of PrP5.

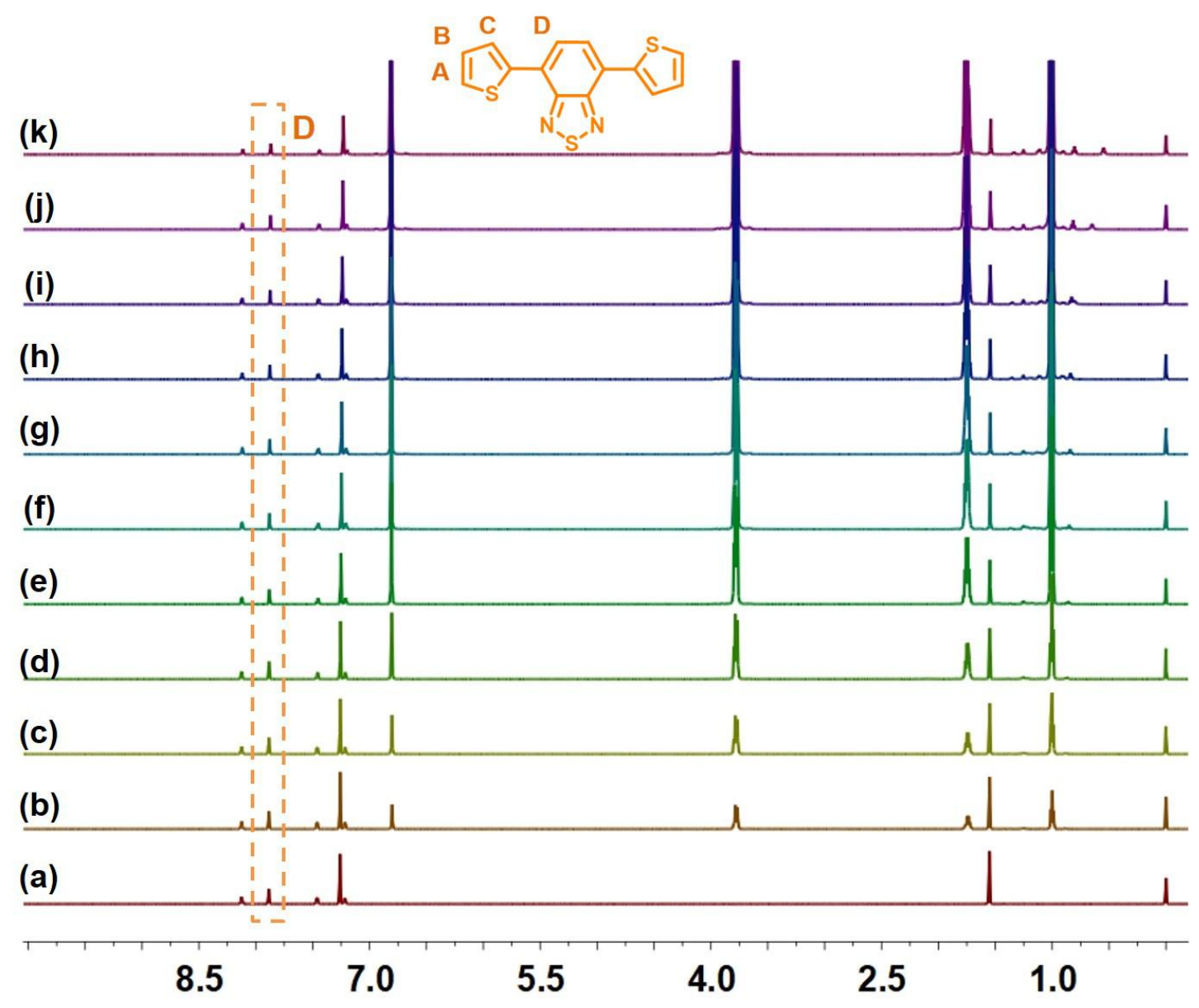


Figure S10 ${ }^{1} \mathrm{H}$ NMR spectra $\left(600 \mathrm{MHz}, \mathrm{CDCl}_{3}, 293 \mathrm{~K}\right)$ of DTBT at a concentration of $1.00 \mathrm{mM}$ with different concentrations of PrP5: (a) $0 \mathrm{mM}$, (b) $0.383 \mathrm{mM}$, (c) 0.647 $\mathrm{mM}$, (d) $1.08 \mathrm{mM}$, (e) $2.19 \mathrm{mM}$, (f) $2.95 \mathrm{mM}$, (g) $3.77 \mathrm{mM}$, (h) $4.62 \mathrm{mM}$, (i) 5.47 $\mathrm{mM},(\mathrm{j}) 7.26 \mathrm{mM}$, and (k) $9.12 \mathrm{mM}$.

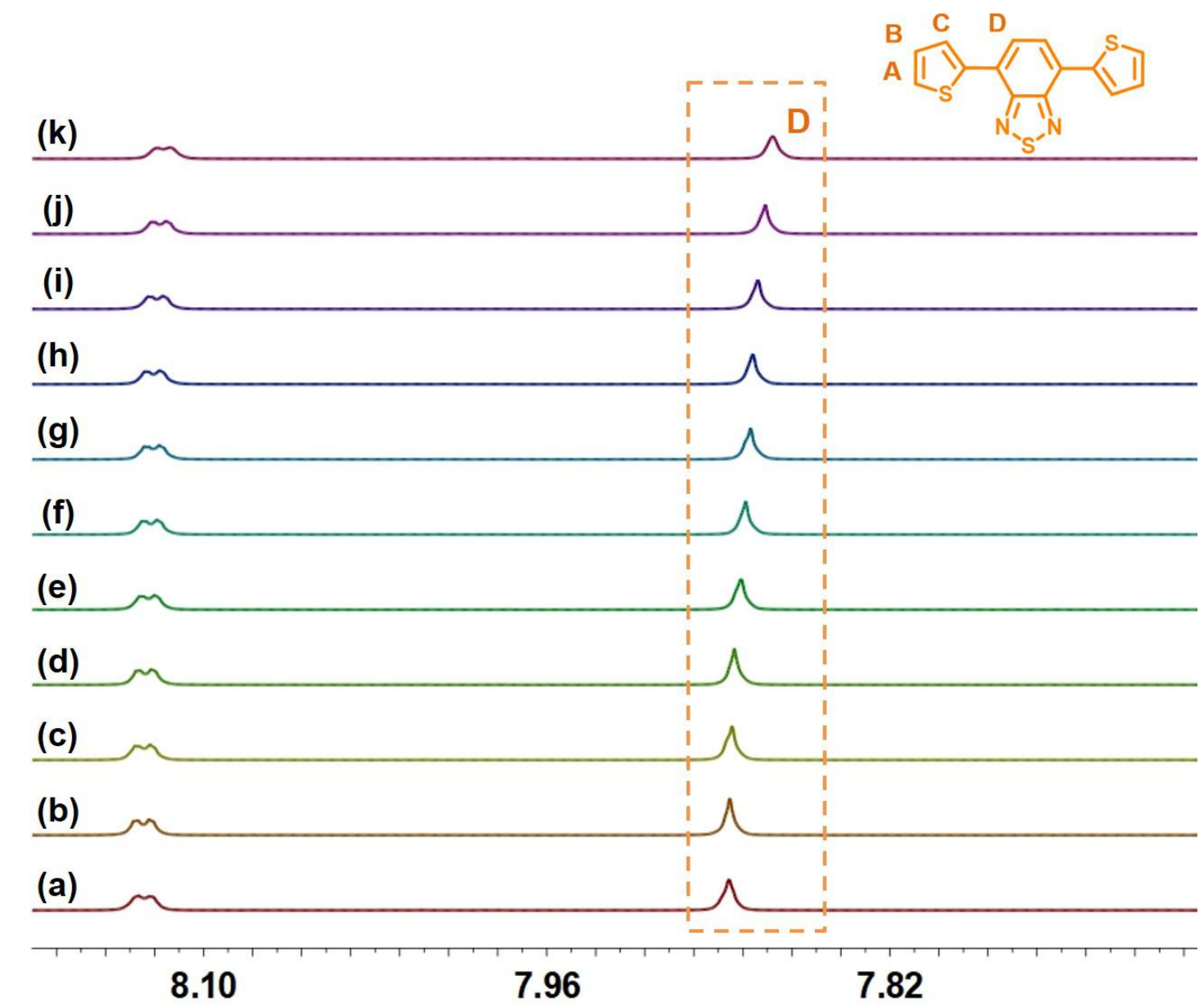

Figure S11 Partial ${ }^{1} \mathrm{H}$ NMR spectra $\left(600 \mathrm{MHz}, \mathrm{CDCl}_{3}, 293 \mathrm{~K}\right)$ of DTBT at a concentration of $1.00 \mathrm{mM}$ with different concentrations of PrP5: (a) $0 \mathrm{mM}$, (b) 0.383 mM, (c) $0.647 \mathrm{mM}$, (d) $1.08 \mathrm{mM}$, (e) $2.19 \mathrm{mM}$, (f) $2.95 \mathrm{mM}$, (g) $3.77 \mathrm{mM}$, (h) 4.62 $\mathrm{mM}$, (i) $5.47 \mathrm{mM}$, (j) $7.26 \mathrm{mM}$, and (k) $9.12 \mathrm{mM}$. 


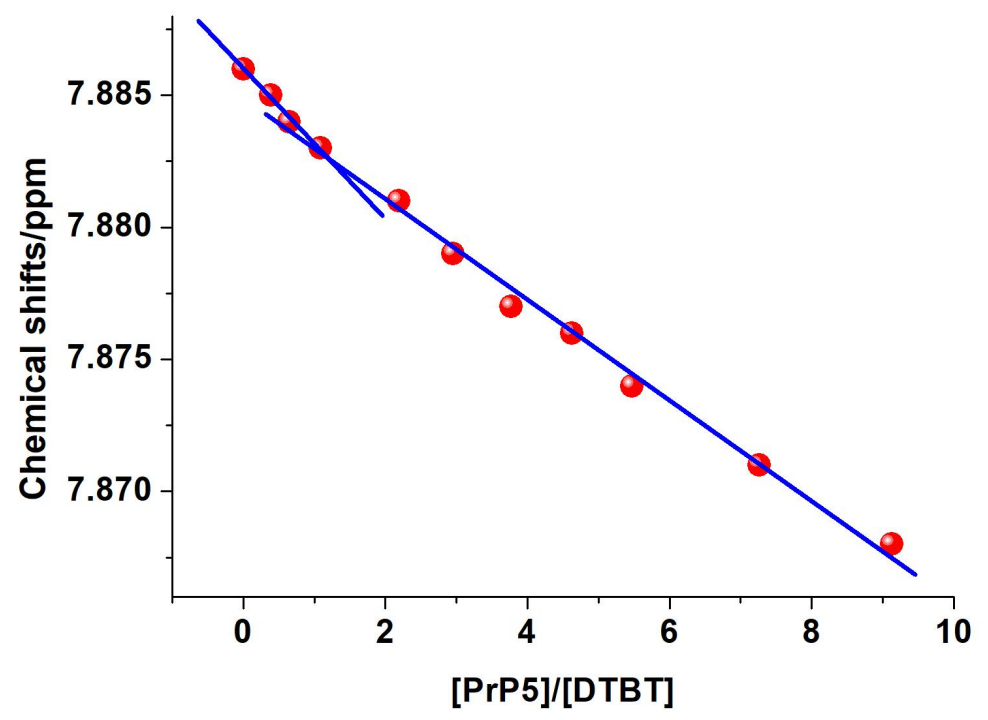

Figure S12 Molar ratio plot for the complexation between PrP5 and DTBT in $\mathrm{CDCl}_{3}$, indicating a 1:1 binding stoichiometry.

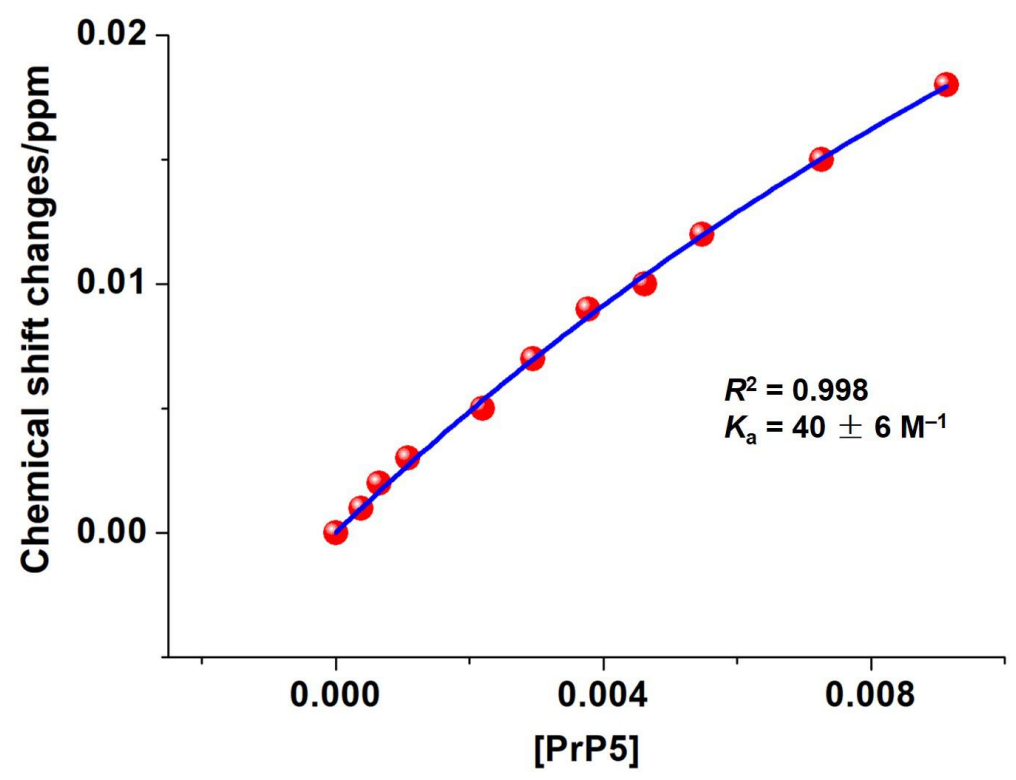

Figure S13 The chemical shift changes of $\mathrm{H}_{\mathrm{D}}$ on DTBT upon addition of PrP5 in $\mathrm{CDCl}_{3}$. The blue solid line was obtained from the non-linear curve-fitting using Eq. S2. 


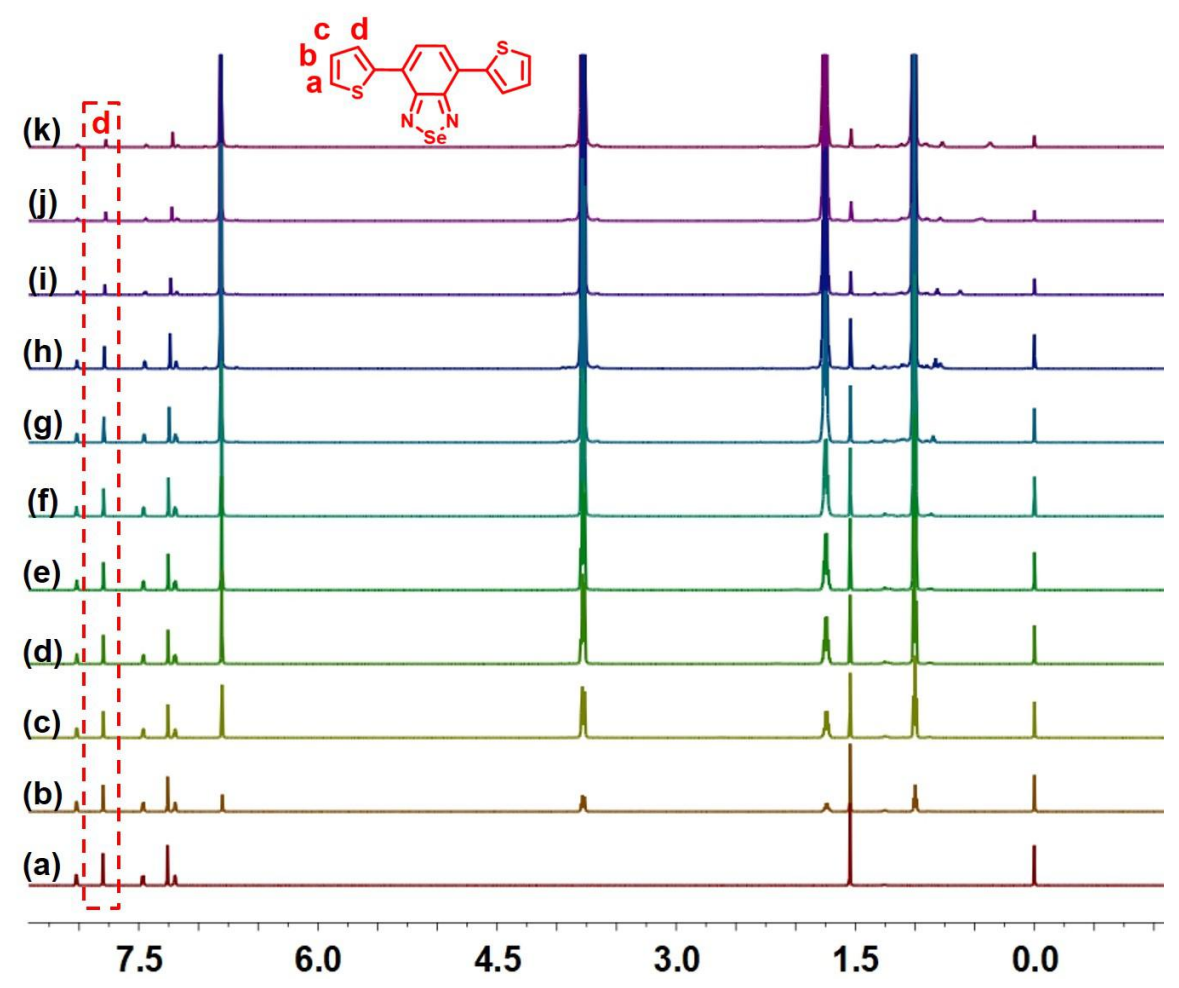

Figure S14 ${ }^{1} \mathrm{H}$ NMR spectra $\left(600 \mathrm{MHz}, \mathrm{CDCl}_{3}, 293 \mathrm{~K}\right)$ of DTBS at a concentration of $1.00 \mathrm{mM}$ with different concentrations of PrP5: (a) $0 \mathrm{mM}$, (b) $0.400 \mathrm{mM}$, (c) 0.620 mM, (d) $1.05 \mathrm{mM}$, (e) $1.33 \mathrm{mM}$, (f) $1.85 \mathrm{mM}$, (g) $4.09 \mathrm{mM}$, (h) $6.50 \mathrm{mM}$, (i) 9.36 mM, (j) $15.8 \mathrm{mM}$, and (k) $20.4 \mathrm{mM}$.

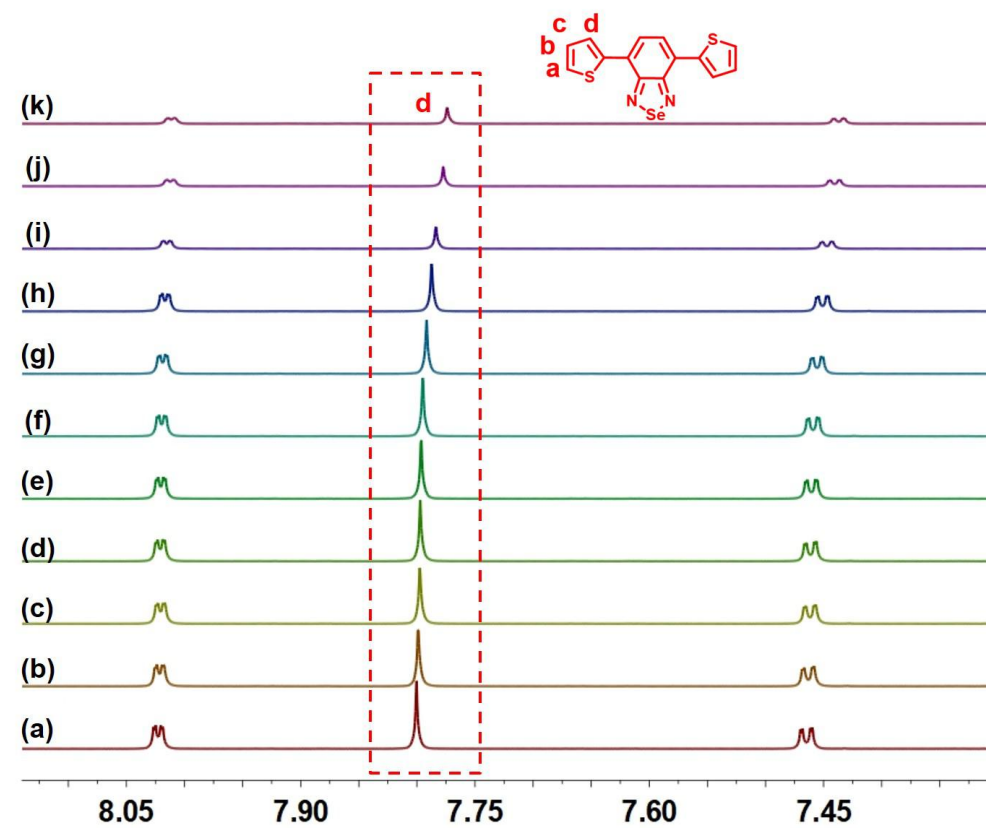

Figure S15 Partial ${ }^{1} \mathrm{H}$ NMR spectra $\left(600 \mathrm{MHz}, \mathrm{CDCl}_{3}, 293 \mathrm{~K}\right)$ of DTBS at a concentration of $1.00 \mathrm{mM}$ with different concentrations of PrP5: (a) $0 \mathrm{mM}$, (b) 0.400 mM, (c) $0.620 \mathrm{mM}$, (d) $1.05 \mathrm{mM}$, (e) $1.33 \mathrm{mM}$, (f) $1.85 \mathrm{mM}$, (g) $4.09 \mathrm{mM}$, (h) 6.50 mM, (i) $9.36 \mathrm{mM}$, (j) $15.8 \mathrm{mM}$, and (k) $20.4 \mathrm{mM}$. 


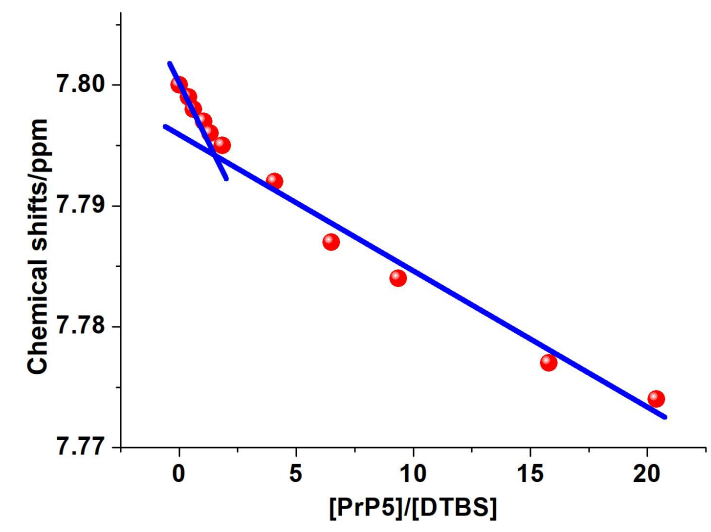

Figure S16 Molar ratio plot for the complexation between PrP5 and DTBS in $\mathrm{CDCl}_{3}$, indicating a 1:1 binding stoichiometry.

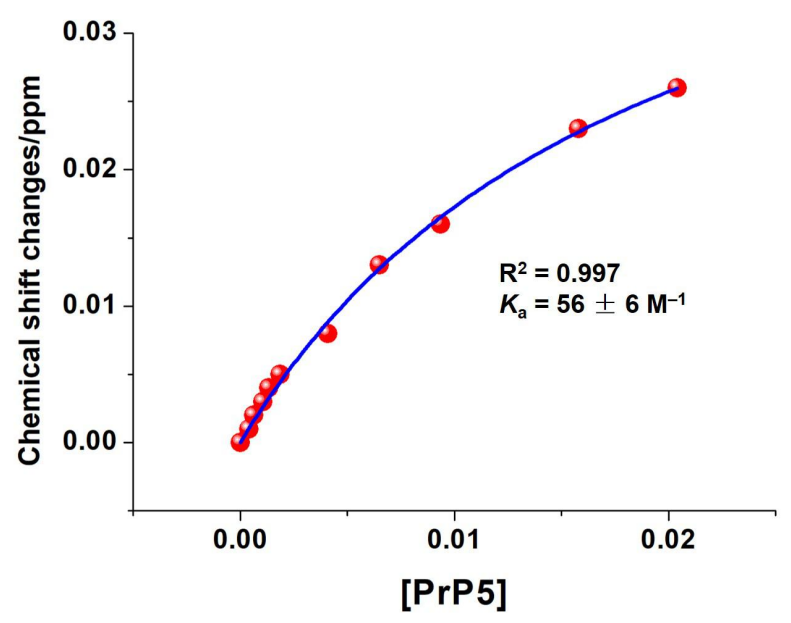

Figure S17 The chemical shift changes of $H_{d}$ on DTBS upon addition of PrP5 in $\mathrm{CDCl}_{3}$. The blue solid line was obtained from the non-linear curve-fitting using Eq. S2. 
8. Concentration-dependent ${ }^{1} \mathrm{H}$ NMR studies of DTBS and PrP5 in $\mathrm{CDCl}_{3}$

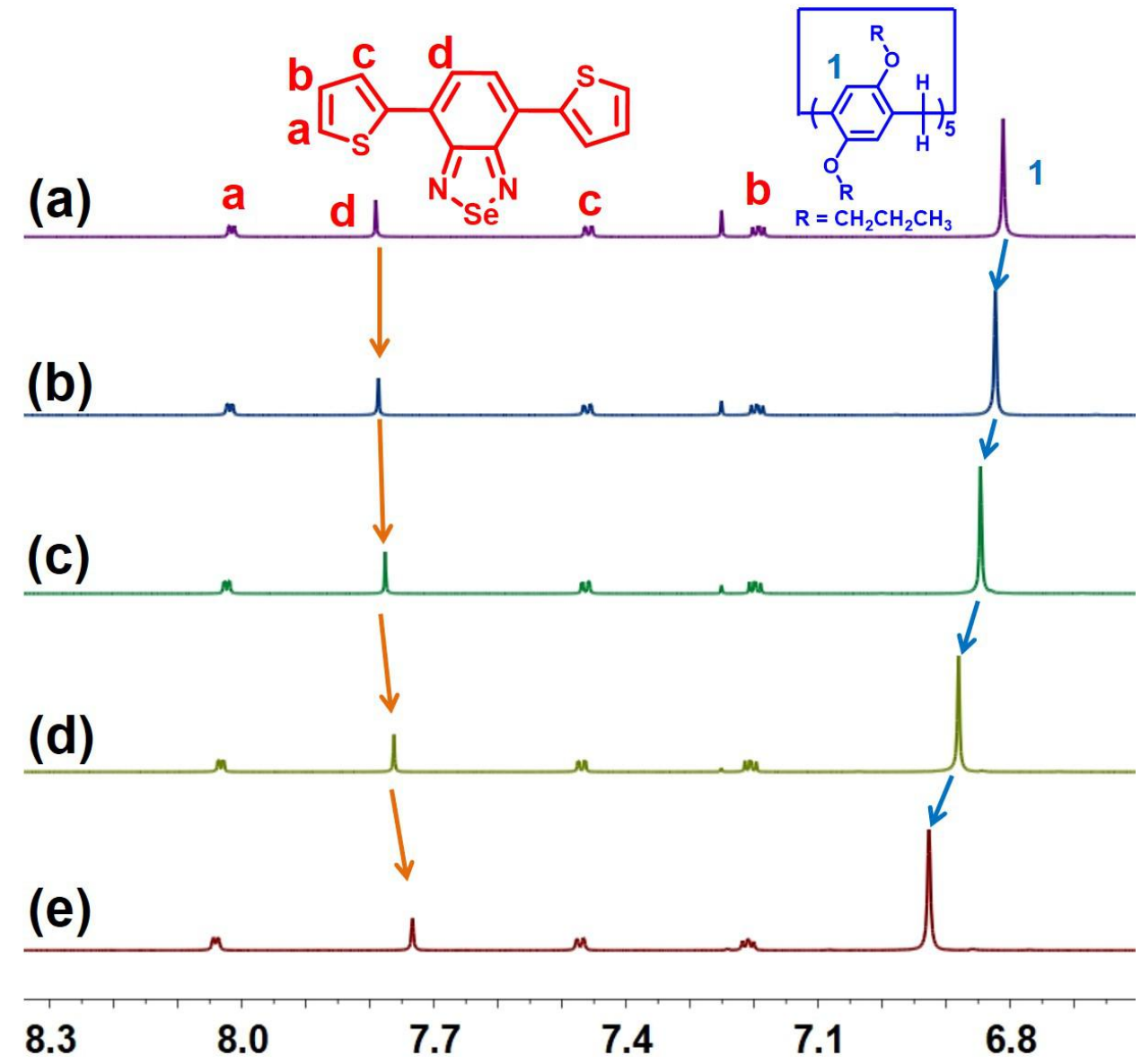

Figure S18 Partial ${ }^{1} \mathrm{H}$ NMR (500 MHz, CDCl $\left.3,293 \mathrm{~K}\right)$ spectra of PrP5 and DTBS at different concentrations: (a) $12.0 \mathrm{mM}$, (a) $25.0 \mathrm{mM}$, (c) $50.0 \mathrm{mM}$, (d) $100 \mathrm{mM}$, and (f) $200 \mathrm{mM}$. 
9. Concentration dependence of the diffusion coefficient of DTBT and DTBS with PrP5 in $\mathrm{CDCl}_{3}$

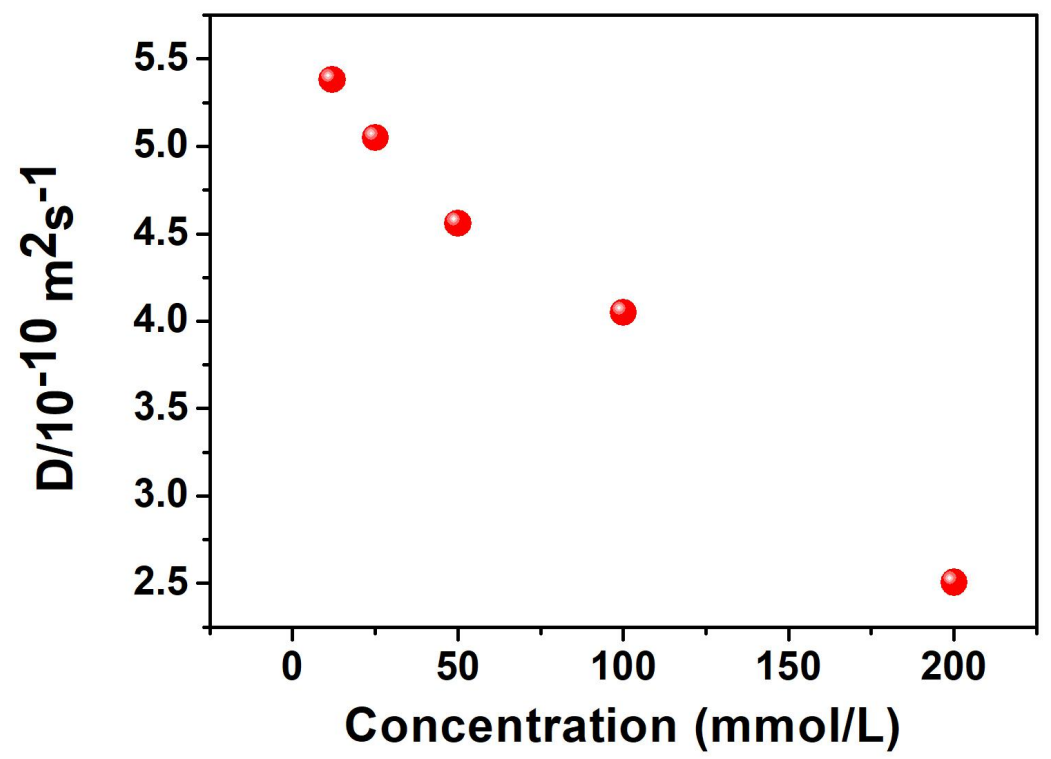

Figure S19 DOSY (500 MHz, $298 \mathrm{~K})$ plot of $\mathrm{CDCl}_{3}$ solutions of DTBT and PrP5 at multiple concentrations.

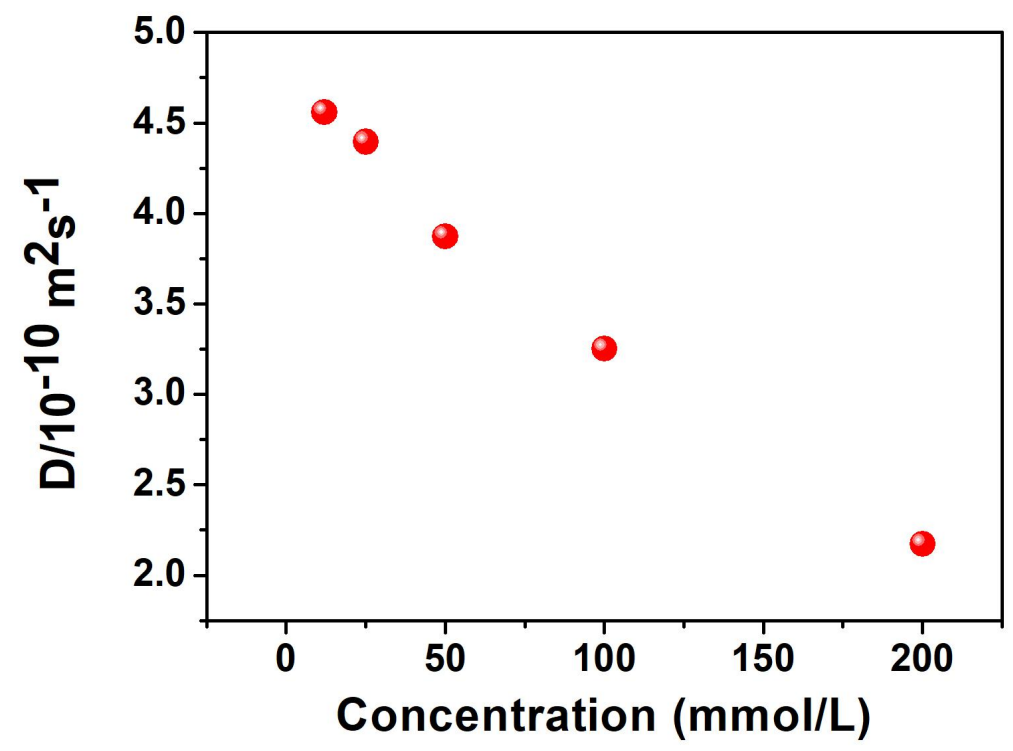

Figure S20 DOSY $(500 \mathrm{MHz}, 298 \mathrm{~K})$ plot of $\mathrm{CDCl}_{3}$ solutions of DTBS and PrP5 at multiple concentrations. 
10. X-ray crystal data of PrP5 $\supset$ DTBT and PrP5 $\supset$ DTBS

\begin{tabular}{|c|c|c|}
\hline Formula & PrP5 $\supset$ DTBT & PrP5 $\supset$ DTBS \\
\hline Crystallization Solvent & isopropyl ether & isopropyl ether \\
\hline Collection Temperature & $170 \mathrm{~K}$ & $170 \mathrm{~K}$ \\
\hline Sum Formula & $\mathrm{C}_{79} \mathrm{H}_{98} \mathrm{~N}_{2} \mathrm{O}_{10} \mathrm{~S}_{3}$ & $\mathrm{C}_{79} \mathrm{H}_{98} \mathrm{~N}_{2} \mathrm{O}_{10} \mathrm{~S}_{2} \mathrm{Se}$ \\
\hline$M r$ & 1331.77 & 1378.67 \\
\hline Crystal System & Monoclinic & Monoclinic \\
\hline Space Group & $\mathrm{P} 2{ }_{1} / \mathrm{n}$ & $\mathrm{P} 2{ }_{1} / \mathrm{n}$ \\
\hline$a[\AA]$ & $21.0778(6)$ & $21.0641(8)$ \\
\hline$b[\AA]$ & $12.4167(3)$ & $12.3917(6)$ \\
\hline$c[\AA]$ & $27.6753(6)$ & $27.6418(9)$ \\
\hline$\alpha\left[^{\circ}\right]$ & 90 & 90 \\
\hline$\beta\left[^{\circ}\right]$ & $93.4650(10)$ & $93.4180(10)$ \\
\hline$\gamma\left[^{\circ}\right]$ & 90 & 90 \\
\hline$V[\AA 3]$ & $7229.8(3)$ & $7202.2(5)$ \\
\hline$Z$ & 4 & 4 \\
\hline $\mathrm{Dcalcd}[\mathrm{g} \mathrm{cm}-3]$ & 1.224 & 1.271 \\
\hline$\mu[\mathrm{mm}-1]$ & 0.162 & 0.639 \\
\hline $\mathrm{F}(000)$ & 2856.0 & 2928.0 \\
\hline $2 \theta$ range $\left[^{\circ}\right]$ & $4.412-52.734$ & $4.418-52.818$ \\
\hline Reflections collected & 47640 & 60634 \\
\hline Independent reflections, Rint & $14749,0.0533$ & $14756,0.0822$ \\
\hline Data /restraints /parameters & $14749 / 114 / 963$ & $14756 / 243 / 954$ \\
\hline Final $R 1$ values $(I>=2 \sigma(I))$ & 0.0777 & 0.0719 \\
\hline Final $R 1$ values (all data) & 0.1233 & 0.1321 \\
\hline Final $w R\left(F_{2}\right)$ values (all data) & 0.2467 & 0.2305 \\
\hline Goodness-of-fit on $F^{2}$ & 1.023 & 1.020 \\
\hline Largest difference peak and hole [e.A-3] & $0.77 /-0.92$ & $0.41 /-1.13$ \\
\hline $\mathrm{CCDC}$ & 1957544 & 1957546 \\
\hline
\end{tabular}

Crystals of PrP5 $\supset$ DTBT and PrP5 $\supset$ DTBS were grown by slow evaporation of a $2.00 \mathrm{~mL}$ isopropyl ether solution containing $2.00 \mathrm{mM}$ PrP5 and $2.00 \mathrm{mM}$ DTBT or DTBS. 


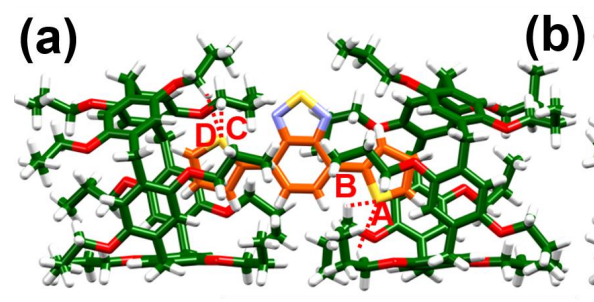

(d)

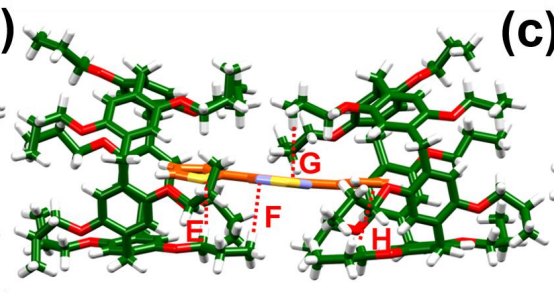

Side view (c)

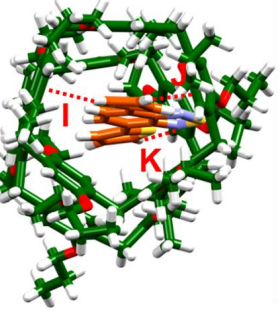

Top view

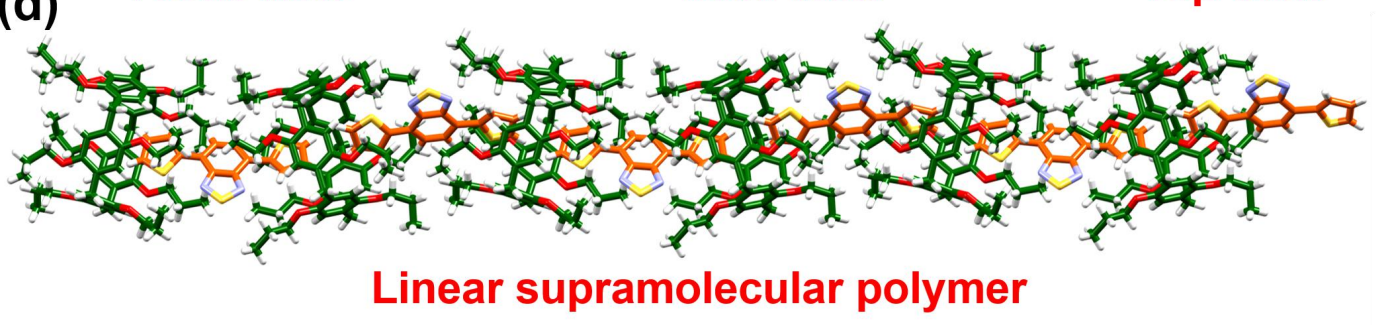

Figure S21. $(\mathrm{a}-\mathrm{c})$ Different views of the crystal structure of PrP5 $\supset$ DTBT. (d) The corresponding packing structure in the solid state to show the formation of a linear supramolecular polymer chain from PrP5 $\supset$ DTBT. For PrP5, carbon atoms are green, oxygen atoms are red, and hydrogen atoms are white. For DTBT, carbon atoms are orange, nitrogen atoms are purple, sulfur atoms are yellow, and hydrogen atoms are white. $\mathrm{C}-\mathrm{H} \cdots \mathrm{S}$ interaction parameters: $\mathrm{C}-\mathrm{H} \cdots \mathrm{S}$ distances $(\AA), \mathrm{C}-\mathrm{H} \cdots \mathrm{S}$ angles $(\mathrm{deg})$ : A: $2.87,137 ; \mathbf{B}: 2.93,118 ; \mathbf{C}: 2.80,159 ; \mathbf{D}: 2.94,128 . \mathrm{C}-\mathrm{H} \cdots \pi$ interaction parameters: $\mathrm{C}-\mathrm{H} \cdots \pi$ distances $(\AA), \mathrm{C}-\mathrm{H} \cdots \pi$ angles $(\mathrm{deg}): \mathbf{E}: 2.80,151 ; \mathbf{F}: 2.83$, 150; G: 2.86, 166; H: 2.88, 145; I: 2.97, 133; J: 2.84, 135; K: 2.94, 128.

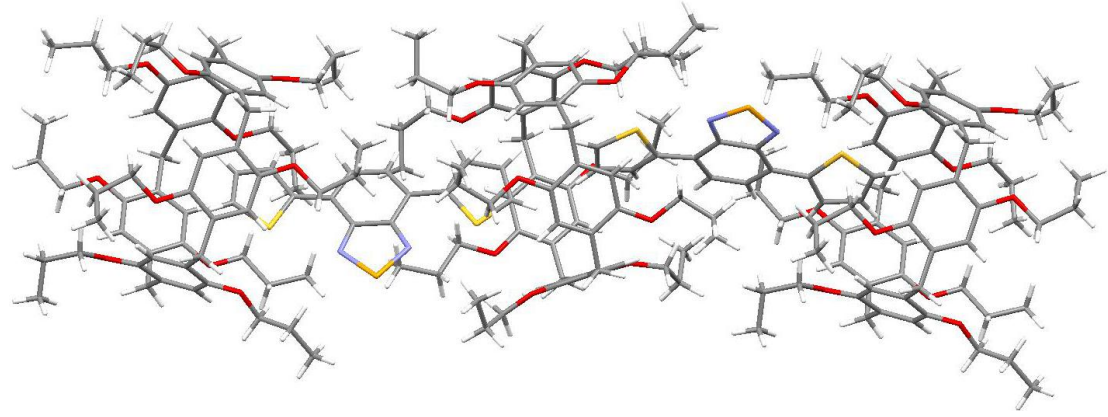

Figure S22 The crystal structure of PrP5 $\supset$ DTBS.

In the crystal structure of PrP5 $\supset$ DTBT and PrP5 $\supset$ DTBS, the thiophene groups were disordered because of rotation about the single bonds. Some H atoms on PrP5 were also disordered. 

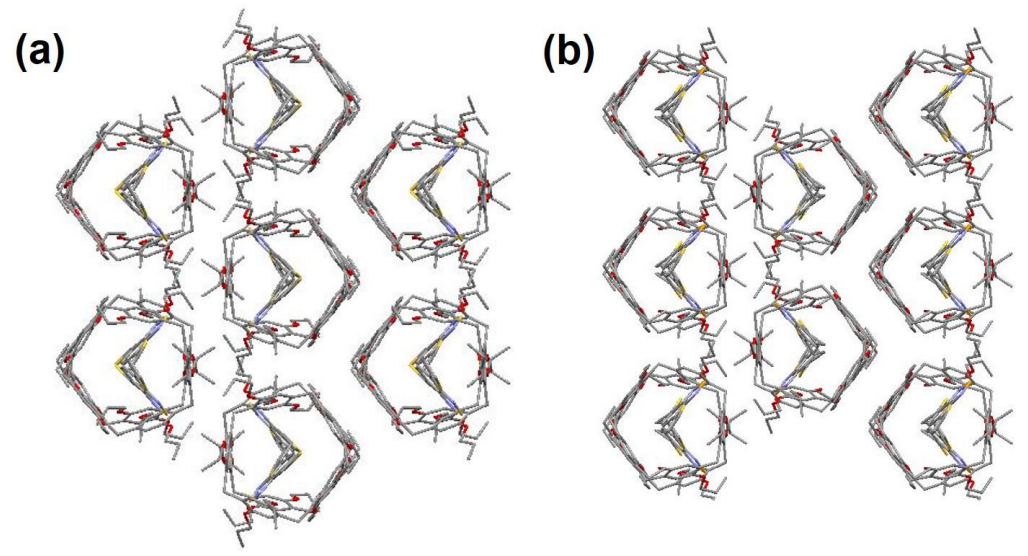

Figure S23 Packing structures of (a) PrP5 $\supset$ DTBT and (b) PrP5 $\supset$ DTBS. Hydrogen atoms are omitted for clarity.

\section{The PL/PLE spectra and TCSPC decay curves of DTBS and PrP5 $D$ DTBS}

(a)

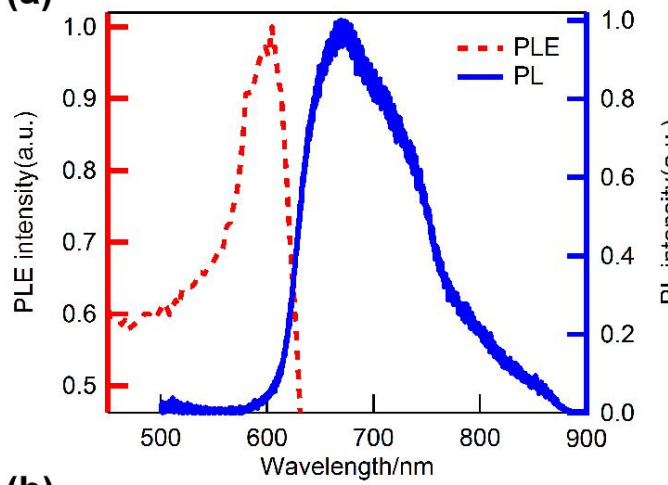

(b)

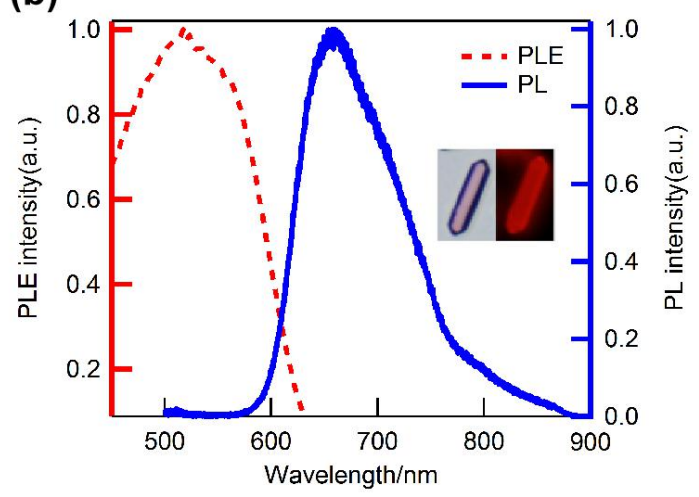

(c)

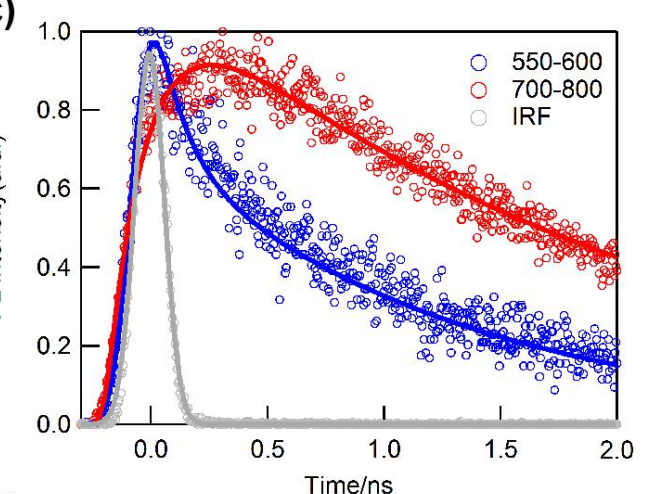

(d)

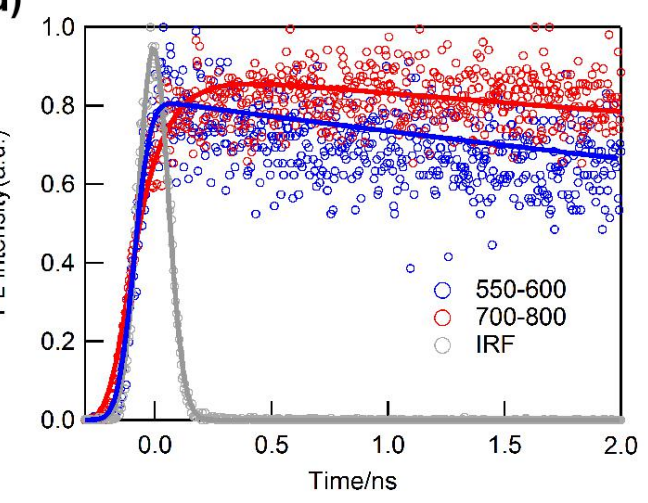

Figure S24 PL and PLE spectra of (a) DTBS and (b) PrP5 $\supset$ DTBS crystals (the inset pictures showed the color and fluorescence emission of single crystals of PrP5 $\supset$ DTBS). TCSPC decay curves of specific emission wavelength range of (c) DTBS and (d) PrP5 $\supset$ DTBS crystals. These data were acquired under $460 \mathrm{~nm}$ laser excitation except for the PLE spectra. 
The single crystal of DTBS shows a red emission with a major PL peak at 658 $\mathrm{nm}$ and a lowest energy absorption peak at $601 \mathrm{~nm}$ (Figure S24a). The PrP5 $\supset$ DTBS cocrystal shows a blue-shifted emission with peak at $647 \mathrm{~nm}$ and a PLE peak at $\sim 520$ $\mathrm{nm}$ (Figure S24b). Interestingly, in addition to the main peak at $658 \mathrm{~nm}$, PL of the DTBS crystal shows a notable low energy shoulder peak at $\sim 720 \mathrm{~nm}$, which is significantly reduced in the PrP5 $\supset$ DTBS crystal. We further measured the excited state PL decay process at different emission wavelengths to confirm the excimer formation in DTBS but not in PrP5 $\supset$ DTBS and the results are plotted in Figure S24c and S24d. We compared with PL decay at blue side of main PL peak (550-600 nm) and the shoulder peak (700-800 nm). Interestingly, the main peak of DTBS shows an instrument response function (IRF) limited rising process and a major fast decay with a lifetime of $\sim 150 \mathrm{ps}$. This fast decay matches very well with the rising dynamics of the shoulder peak, confirming excimer formation in DTBS crystal. On the contrary, negligible conversion to excimer was observed in the PrP5 $\supset$ DTBS crystal and the PL shows a long lifetime of $\sim 10 \mathrm{~ns}$, indicating the suppression of excimer formation and ACQ effect.

\section{Photographs of DTBT, PrP5 $\supset$ DTBT, DTBS, and PrP5 $\supset$ DTBS under a UV lamp}
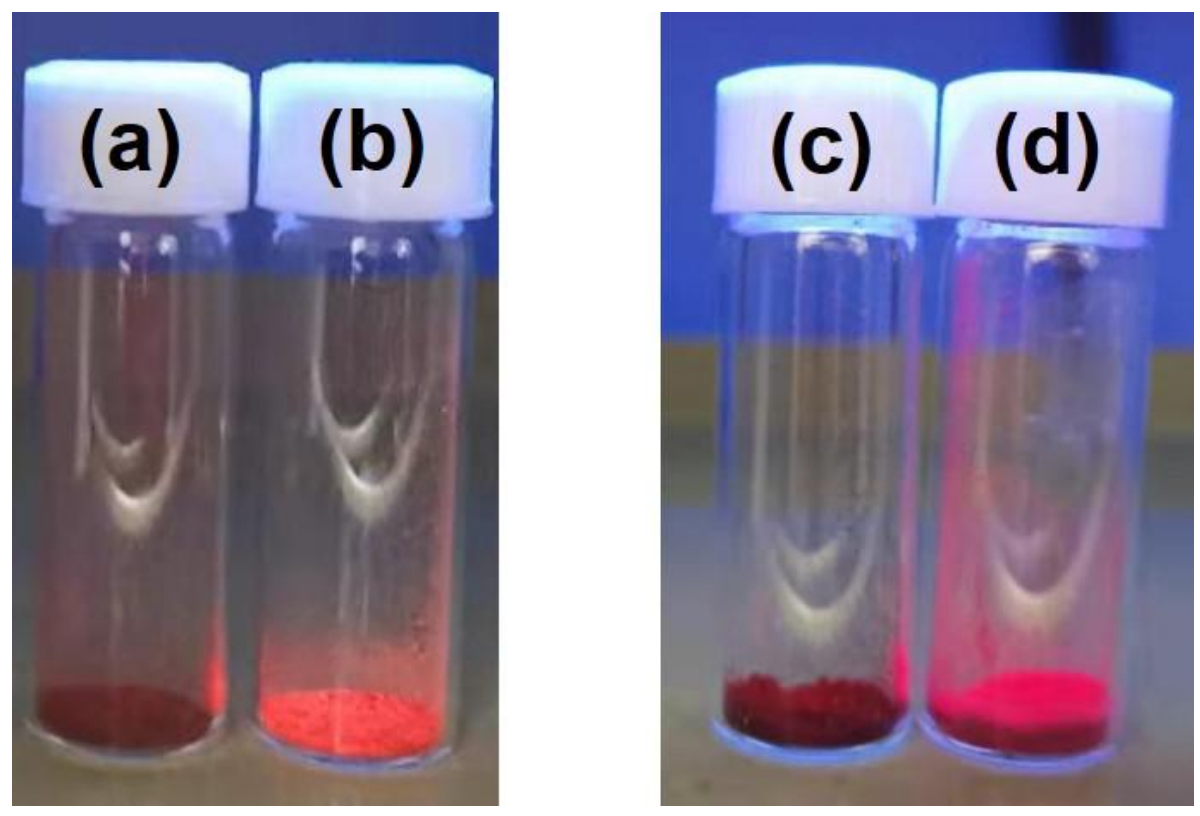

Figure S25 Photographs of samples (a) DTBT, (b) PrP5 $\supset$ DTBT, (c) DTBS, and (d) PrP5 $\supset$ DTBS upon excitation at $365 \mathrm{~nm}$ using a UV lamp at $298 \mathrm{~K}$. 
13. TCSPC decay curves of DTBT, DTBS, PrP5 $\supset$ DTBT, and PrP5 $\supset$ DTBS crystals.

(a)

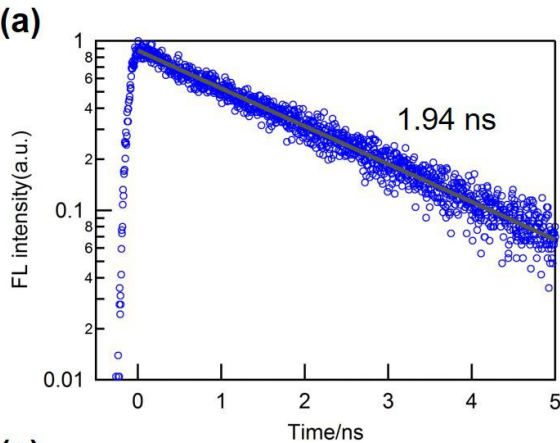

(c)

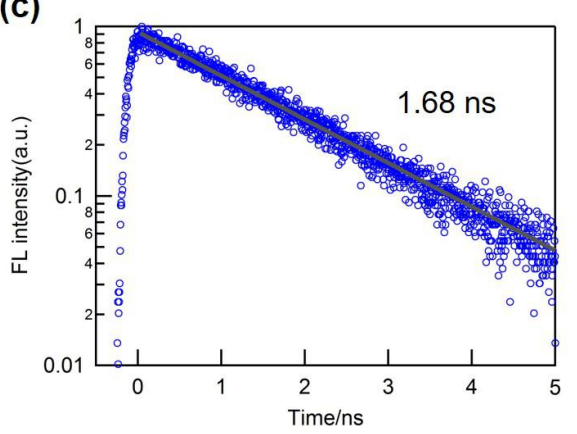

(b)

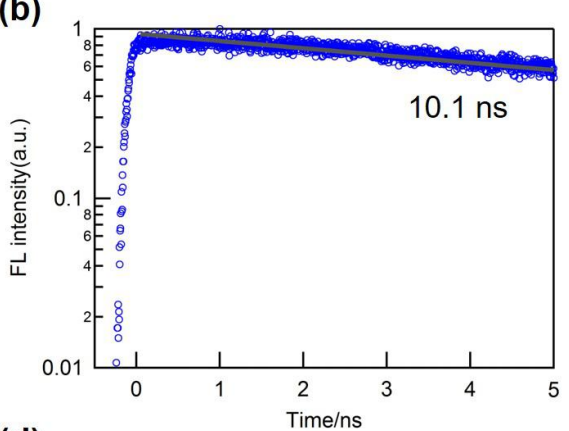

(d)

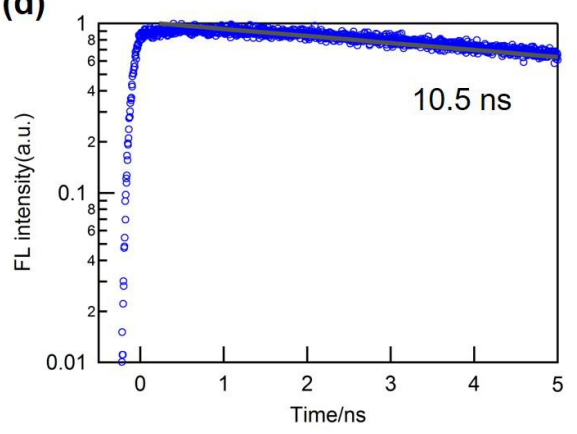

Figure S26 TCSPC decay curves of (a) a DTBT crystal, (b) a PrP5 $\supset$ DTBT crystal, (c) a DTBS crystal, and (d) a PrP5 $\supset$ DTBS crystal with all emission wavelengths collected .

\section{References}

S1. Yu, G.; Han, C.; Zhang, Z.; Chen, J.; Yan, X.; Zheng, B.; Liu, S.; Huang, F. Pillar[6]arene-Based Photoresponsive Host-Guest Complexation. J. Am. Chem. Soc. 2012, 134, 8711-8717.

S2. Li, X.; Zeng, W.; Zhang, Y.; Hou, Q.; Yang, W.; Cao, Y. Synthesis and Properties of Novel Poly(p-phenylenevinylene) Copolymers for Near-infrared Emitting Diodes. Eur. Polym. J. 2005, 41, 2923-2933.

S3 Frisch, M. J.; Trucks, G. W.; Schlegel, H. B.; Scuseria, G. E.; Robb, M. A.; Cheeseman, J. R.; Scalmani, G.; Barone, V.; Petersson, G. A.; Nakatsuji, H.; Li, X.; Caricato, M.; Marenich, A. V.; Bloino, J.; Janesko, B. G.; Gomperts, R.; Mennucci, B.; Hratchian, H. P.; Ortiz, J. V.; Izmaylov, A. F.; Sonnenberg, J. L.; Williams-Young, D.; Ding, F.; Lipparini, F.; Egidi, F.; Goings, J.; Peng, B.; Petrone, A.; Henderson, T.; Ranasinghe, D.; Zakrzewski, V. G.; Gao, J.; Rega, N.; Zheng, G.; Liang, W.; Hada, M.; Ehara, M.; Toyota, K.; Fukuda, R.; Hasegawa, J.; Ishida, M.; Nakajima, T.; Honda, Y.; Kitao, O.; Nakai, H.; Vreven, T.; Throssell, K.; Montgomery, J. A.; Peralta, J. E.; Ogliaro, F.; Bearpark, M. J.; Heyd, J. J.; Brothers, E. N.; Kudin, K. N.; Staroverov, V. N.; Keith, T. 
A.; Kobayashi, R.; Normand, J.; Raghavachari, K.; Rendell, A. P.; Burant, J. C.; Iyengar, S. S.; Tomasi, J.; Cossi, M.; Millam, J. M.; Klene, M.; Adamo, C.; Cammi, R.; Ochterski, J. W.; Martin, R. L.; Morokuma, K.; Farkas, O.; Foresman, J. B.; Fox, D. J. Gaussian 16, revision A.03. Gaussian Inc.: Wallingford, CT, 2016.

S4 Scrocco, E.; Tomasi, J. The Electrostatic Molecular Potential as a Tool for the Interpretation of Molecular Properties, in "Topics in Current Chemistry, New Concepts II”, p. 95, Springer-Verlag, New York, 1973.

S5 Roy D.; Todd K.; John M. Gaussview, Version 6, Semichem Inc., Shawnee Mission, KS, 2016.

S6 Xia, W.; Hu, X.-Y.; Chen, Y.; Lin, C.; Wang, L., A Novel Redox-Responsive Pillar[6]arene-Based Inclusion Complex with A Ferrocenium Guest. Chem. Commun. 2013, 49, 5085-5087. 